\title{
Prognostic Value of the Combination of CEA and Fibrinogen/Albumin Ratio in Resectable Gastric Cancer
}

This article was published in the following Dove Press journal: Cancer Management and Research

\section{Junbin Zhang (D) \\ Jiayin Ruan \\ Weibin Wang \\ Yimin Lu \\ Haiyong Wang (D) \\ Xiongfei Yu \\ Haohao Wang \\ Lisong Teng}

Department of Surgical Oncology, The First Affiliated Hospital, College of Medicine, Zhejiang University, Hangzhou, People's Republic of China
Correspondence: Haohao Wang; Lisong Teng

Tel/Fax +86 57/8723688 |

Email coldhot33@I26.com;

Isteng@zju.edu.cn
Purpose: To investigate the prognostic value of combined serum carcinoembryonic antigen (CEA) levels and fibrinogen/albumin ratio (FAR) in patients with resectable gastric cancer (GC).

Introduction: This retrospective study evaluated the CEA, fibrinogen, and albumin levels and other clinicopathological features of GC patients. The prognostic significance of these factors for overall survival (OS) was assessed using Kaplan-Meier curves and univariate and multivariate Cox proportional models.

Patients and Methods: A total of 267 patients were included. The optimal cutoff values of CEA and FAR were $3.2 \mathrm{ng} / \mathrm{mL}$ and 0.086 , respectively. Patients were stratified into three groups based on this cutoff value: CEA-FAR $=0($ CEA $<3.2 \mathrm{ng} / \mathrm{mL}$ and FAR $<0.086)$, CEA-FAR $=1$ $(\mathrm{CEA} \geq 3.2 \mathrm{ng} / \mathrm{mL}$ or FAR $\geq 0.086)$, and CEA-FAR $=2(\mathrm{CEA} \geq 3.2 \mathrm{ng} / \mathrm{mL}$ and $\mathrm{FAR} \geq 0.086)$.

Results: Higher CEA-FAR was strongly associated with age, tumor size, tumor invasion, lymph node status, and TNM stage (all $\mathrm{P}<0.05$ ). The OS rates differed significantly between these 3 groups ( $88.9 \%$ vs $65.0 \%$ vs $46.9 \%, \mathrm{P}<0.001)$. Multivariate analysis showed that CEA-FAR was an independent prognostic factor for OS $(\mathrm{P}<0.001)$. The area under the curve was larger for CEA-FAR than for either CEA or FAR alone (0.683, 0.644, and 0.669 , respectively).

Conclusion: Preoperative CEA-FAR could be a potential blood marker for predicting tumor progression and the prognosis of GC patients. Patients with a higher CEA-FAR should undergo extensive follow-up.

Keywords: gastric carcinoma, patients, survival, risk factor

\section{Introduction}

Gastric cancer (GC) is among the most common malignant tumors of the digestive tract and has a high risk of recurrence and distant metastasis. In China, GC has the second highest incidence rate and third highest mortality rate among all types of cancer. ${ }^{1}$ Preoperative evaluation is crucial in the treatment of GC. Therefore, it is crucial to find a simple and convenient preoperative prognostic factor to identify high-risk patients and to guide further treatment.

Fibrinogen, a glycoprotein synthesized by the liver, is produced in response to inflammation or activation of the coagulation system and plays an important role in the coagulation cascade. ${ }^{2}$ Inflammation is a hallmark of cancer, and malignant tumors compromise the coagulation, anticoagulation, and fibrinolysis systems of the body through various mechanisms, resulting in abnormal coagulation function and fibrinogen elevation. ${ }^{3}$ Fibrinogen is an acute-phase-response protein that can 
increase under systemic inflammatory conditions. Previous studies have shown that increased plasma fibrinogen indicates poor prognosis of various cancers including GC. ${ }^{4,5}$ Malnutrition is a common clinical manifestation of gastrointestinal cancers and is also a prognostic indicator of cancer. Albumin is commonly used to assess nutritional status, and hypoalbuminemia is associated with poor prognosis in several cancers such as lung, gastric, and colon cancers. ${ }^{6}$ Both an increase in serum fibrinogen and a decrease in albumin are associated with systemic inflammation. ${ }^{4,6}$ Furthermore, it has been recently reported that the fibrinogen-to-albumin ratio (FAR) can be used as a biomarker to predict the prognosis of various cancers such as hepatocellular carcinoma, breast cancer, and gallbladder cancer, ${ }^{7-9}$ however, the role of FAR in GC remains relatively unexplored.

Tumor markers can serve as indicators for the diagnosis, treatment, and prognosis of GC. CEA is a common serum marker for malignant gastrointestinal tumors and is important in the diagnosis of GC; CEA expression is also an independent risk factor for poor prognosis in GC. ${ }^{10}$ We hypothesized that a combination of tumor and patient characteristics can be used to predict the survival of GC patients. Accordingly, this study aimed to evaluate the clinical value of CEA-FAR as a novel prognostic biomarker in GC. Further, we also evaluated the association between CEA-FAR and the clinicopathological features of GC.

\section{Patients and Methods}

\section{Patients}

This retrospective study evaluated patients with primary GC who underwent radical gastrectomy between June 2012 and June 2016 in the Department of Surgical Oncology, the First Affiliated Hospital, Medical of College, Zhejiang University. The inclusion criteria were: (1) complete patient data (including sex, age, pathological type, tumor-node-metastasis (TNM) stage, and survival); (2) no neoadjuvant chemotherapy or radiotherapy prior to surgery; (3) undergone radical gastrectomy with confirmation of adenocarcinoma by postoperative pathology; (4) no metastasis to the lung, liver, bone, and other organs on preoperative imaging and no distant metastasis found during the surgery. The exclusion criteria were: (1) blood disorders; (2) presence of another cancer; (3) hepatic or renal insufficiency based on abnormal alanine aminotransferase and creatinine levels; (4) palliative surgery or short-circuit operation. This study was approved by the Institutional
Review Board of the First Affiliated Hospital, College of Medicine, Zhejiang University, and this study was conducted in accordance with the Declaration of Helsinki. Because informed consent was deemed unnecessary by the ethical committee, the requirement to obtain written informed consent was waived.

\section{Clinical Data}

Fasting peripheral blood samples were collected within 1 week prior to surgery and sent to the clinical laboratory for routine blood tests and to assess CEA levels, liver and kidney function, coagulation function, and other indicators. FAR was calculated as previously described, ${ }^{11}$ and the neutrophil-to-lymphocyte ratio (NLR) was determined by dividing the neutrophil count by the lymphocyte count.

The clinical data of the GC patients, including age, sex, tumor size, location, degree of differentiation, and tumor stage, were collected from the hospital information system. Staging was done according to the TNM classification of the American Joint Committee on Cancer (8th edition).

\section{Survival and Follow-Up}

All patients were followed up by telephone and outpatient visits after discharge, with the last follow-up conducted in June 2019. Survival time was calculated from the date of diagnosis to date of death or the last follow-up.

\section{Statistical Analysis}

The optimal cutoff values for CEA, FAR, NLR, and other variables were obtained via receiver operating characteristic (ROC) curve analysis. The patients were then divided into 2

Table I Prognostic Scores of CEA, FAR and CEA-FAR

\begin{tabular}{|l|l|}
\hline Scoring System & Score \\
\hline CEA $(\mathrm{ng} / \mathrm{mL})$ & \\
$<3.2$ & 0 \\
$\geq 3.2$ & $\mathrm{I}$ \\
\hline FAR & \\
$<0.086$ & 0 \\
$\geq 0.086$ & $\mathrm{I}$ \\
\hline CEA-FAR & \\
CEA $<3.2$ and FAR $<0.086$ & 0 \\
CEA $\geq 3.2$ or FAR $\geq 0.086$ & 1 \\
CEA $\geq 3.2$ and FAR $\geq 0.086$ & 2 \\
\hline
\end{tabular}

Note: CEA-FAR, combination of CEA and the FAR.

Abbreviations: CEA, carcinoembryonic antigen; FAR, fibrinogen/albumin ratio. 
groups according to the cutoff. Additionally, the patients were divided into 3 groups according to the CEA-FAR score: CEA-FAR $=0(\mathrm{CEA}<3.2 \mathrm{ng} / \mathrm{mL}$ and FAR $<0.086)$, CEA-FAR $=1(C E A \geq 3.2 \mathrm{ng} / \mathrm{mL}$ or FAR $\geq 0.086)$, and CEA$\mathrm{FAR}=2(\mathrm{CEA} \geq 3.2 \mathrm{ng} / \mathrm{mL}$ and FAR $\geq 0.086)$ (Table 1). Chisquare or Fisher's exact test was used for categorical variables. Kaplan-Meier method was used for survival analysis. Multivariate Cox model was used to analyze the factors influencing survival and the prognosis of GC. Variables found significant on univariate analysis were entered into multivariate analysis. All statistical analyses were performed using SPSS 20.0 software, and $\mathrm{P}<0.05$ was considered statistically significant.

\section{Results}

\section{Patient Characteristics}

In total, 267 patients (176 (65.9\%) men and $91(34.1 \%)$ women) with a median age of 63 years (range, 26-91 years) were included in this study. Their clinicopathological characteristics are summarized in Table 2.

Table 2 The Clinicopathological Features of GC Patients

\begin{tabular}{|c|c|c|c|c|c|c|c|}
\hline \multirow[t]{2}{*}{ Features } & \multirow[t]{2}{*}{ Patients, n(\%) } & \multicolumn{3}{|c|}{ CEA (ng/mL) } & \multicolumn{3}{|l|}{ FAR } \\
\hline & & $<3.2$ & $\geq 3.2$ & $P$ value & $<0.086$ & $\geq 0.086$ & $P$ value \\
\hline $\begin{array}{l}\text { Age(years) } \\
\quad<60 \\
\geq 60\end{array}$ & $\begin{array}{l}89(33.3 \%) \\
178(66.7 \%)\end{array}$ & $\begin{array}{l}67 \\
109\end{array}$ & $\begin{array}{l}22 \\
69\end{array}$ & 0.023 & $\begin{array}{l}77 \\
117\end{array}$ & $\begin{array}{l}12 \\
61\end{array}$ & $<0.001$ \\
\hline $\begin{array}{l}\text { Sex } \\
\qquad \text { Female } \\
\text { Male }\end{array}$ & $\begin{array}{l}91(34.1 \%) \\
176(65.9 \%)\end{array}$ & $\begin{array}{l}72 \\
104\end{array}$ & $\begin{array}{l}19 \\
72\end{array}$ & 0.001 & $\begin{array}{l}71 \\
123\end{array}$ & $\begin{array}{l}20 \\
53\end{array}$ & 0.157 \\
\hline $\begin{array}{l}\text { Tumor size }(\mathrm{cm}) \\
\quad<3 \\
\geq 3\end{array}$ & $\begin{array}{l}108(40.4 \%) \\
159(59.6 \%)\end{array}$ & $\begin{array}{l}86 \\
90\end{array}$ & $\begin{array}{l}22 \\
69\end{array}$ & $<0.001$ & $\begin{array}{l}93 \\
101\end{array}$ & $\begin{array}{l}15 \\
58\end{array}$ & $<0.001$ \\
\hline $\begin{array}{l}\text { Tumor location } \\
\text { Upper third } \\
\text { Middle third } \\
\text { Lower third }\end{array}$ & $\begin{array}{l}57(21.3 \%) \\
59(22.1 \%) \\
151(56.6 \%)\end{array}$ & $\begin{array}{l}33 \\
40 \\
103\end{array}$ & $\begin{array}{l}24 \\
19 \\
48\end{array}$ & 0.354 & $\begin{array}{l}41 \\
48 \\
105\end{array}$ & $\begin{array}{l}16 \\
11 \\
46\end{array}$ & 0.223 \\
\hline $\begin{array}{l}\text { Differentiation } \\
\text { Well/moderate } \\
\text { Poor }\end{array}$ & $\begin{array}{l}219(82.0 \%) \\
48(18.0 \%)\end{array}$ & $\begin{array}{l}33 \\
143\end{array}$ & $\begin{array}{l}15 \\
76\end{array}$ & 0.648 & $\begin{array}{l}41 \\
153\end{array}$ & $\begin{array}{l}7 \\
66\end{array}$ & 0.032 \\
\hline $\begin{array}{l}\text { PT status } \\
\text { TI } \\
\text { T2 } \\
\text { T3 } \\
\text { T4 }\end{array}$ & $\begin{array}{l}59(22.1 \%) \\
34(12.7 \%) \\
87(32.6 \%) \\
87(32.6 \%)\end{array}$ & $\begin{array}{l}45 \\
24 \\
60 \\
47\end{array}$ & $\begin{array}{l}14 \\
10 \\
27 \\
40\end{array}$ & 0.029 & $\begin{array}{l}57 \\
26 \\
64 \\
47\end{array}$ & $\begin{array}{l}2 \\
8 \\
23 \\
40\end{array}$ & $<0.001$ \\
\hline $\begin{array}{l}\text { Lymph node metastasis } \\
\text { Negative } \\
\text { Positive }\end{array}$ & $\begin{array}{l}100(37.5 \%) \\
167(62.5 \%)\end{array}$ & $\begin{array}{l}78 \\
98\end{array}$ & $\begin{array}{l}22 \\
69\end{array}$ & 0.001 & $\begin{array}{l}87 \\
107\end{array}$ & $\begin{array}{l}13 \\
60\end{array}$ & $<0.001$ \\
\hline $\begin{array}{l}\text { TNM stage } \\
\text { I } \\
\text { II } \\
\text { III }\end{array}$ & $\begin{array}{l}7 I(26.6 \%) \\
76(28.5 \%) \\
120(44.9 \%)\end{array}$ & $\begin{array}{l}57 \\
51 \\
68\end{array}$ & $\begin{array}{l}14 \\
25 \\
52\end{array}$ & 0.004 & $\begin{array}{l}66 \\
57 \\
71\end{array}$ & $\begin{array}{l}5 \\
19 \\
49\end{array}$ & $<0.001$ \\
\hline $\begin{array}{l}\text { NLR } \\
\quad<2.17 \\
\geq 2.17\end{array}$ & $\begin{array}{l}\mid 36(50.9 \%) \\
|3|(49 . \mid \%)\end{array}$ & $\begin{array}{l}99 \\
77\end{array}$ & $\begin{array}{l}37 \\
54\end{array}$ & 0.019 & $\begin{array}{l}109 \\
85\end{array}$ & $\begin{array}{l}27 \\
46\end{array}$ & 0.006 \\
\hline
\end{tabular}

Note: CEA-FAR: CEA $<3.2$ and FAR $<0.086$ represent 0, CEA $\geq 3.2$ or FAR $\geq 0.086$ represent I, CEA $\geq 3.2$ and FAR $\geq 0.086$ represent 2. Abbreviations: GC, gastric cancer; CEA, carcinoembryonic antigen; FAR, fibrinogen/albumin ratio; TNM, tumor-node-metastasis; NLR, neutrophil-to-lymphocyte ratio. 


\section{Optimal Cutoff Values of CEA and FAR}

The optimal cutoff value of CEA for OS is $3.2 \mathrm{ng} / \mathrm{mL}$ (area under curve, $\mathrm{AUC}=0.644,95 \%$ CI: $0.566-0.723$, $\mathrm{P}<0.001$, Figure 1A). The optimal cutoff value of FAR for $\mathrm{OS}$ is 0.086 (AUC $=0.669,95 \%$ CI: 0.595-0.742, $\mathrm{P}<0.001$, Figure 1A). Based on these cutoff values, patients were divided into 2 groups: high CEA ( $\geq 3.2 \mathrm{ng} /$ $\mathrm{mL}, \mathrm{n}=91)$ and low CEA $(<3.2 \mathrm{ng} / \mathrm{mL}, \mathrm{n}=176)$; high FAR $(\geq 0.086, n=73)$ and low FAR $(<0.086, n=194)$.

The AUC of CEA-FAR for OS (Figure 1B) is 0.683 (95\% CI: 0.614-0.751), which is slightly higher than that of FAR (AUC: 0.669 (95\% CI: 0.595-0.742), Figure 1A) and CEA (AUC: 0.644 (95\% CI: 0.566-0.723), Figure 1A). These results suggest that CEA-FAR may be superior to CEA or FAR alone as a prognostic marker of GC.

\section{Relationship of Preoperative CEA and FAR with Clinicopathological Variables}

Preoperative CEA and FAR were associated with various clinicopathological variables of GC patients (Table 2). High CEA significantly correlated with age $(\mathrm{P}=0.023)$, sex $(\mathrm{P}=0.001)$, tumor size $(\mathrm{P}<0.001)$, tumor invasion $(\mathrm{P}=0.029)$, lymph node metastasis $(\mathrm{P}=0.001)$, and TNM stage $(\mathrm{P}=0.004)$, but not with tumor location and differentiation (all $\mathrm{P}>0.05$ ). Similarly, preoperative FAR significantly correlated with age ( $\mathrm{P}=0.001)$, tumor size $(\mathrm{P}<0.001)$, differentiation $(\mathrm{P}=0.032)$, tumor invasion $(\mathrm{P}<0.001)$, lymph node metastasis ( $\mathrm{P}<0.001)$, and TNM stage $(\mathrm{P}<0.001)$, but not with sex and tumor location (all $\mathrm{P}>0.05$ ).

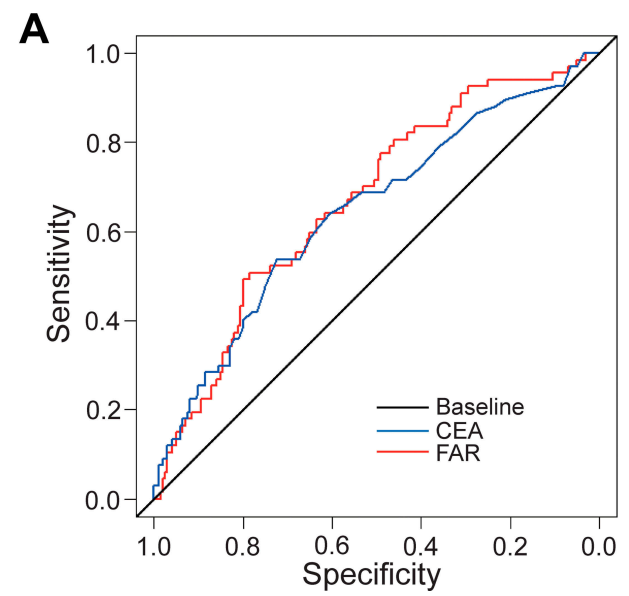

\section{Prognostic Significance of Preoperative CEA and FAR}

Kaplan-Meier analysis and Log rank tests for the prognostic value of preoperative CEA and FAR showed that the OS rate and median OS time of the low CEA group were significantly higher than those of the high CEA group ( 82.4 vs $60.4 \%, 41.0$ vs 39.0 months, $\mathrm{P}<0.001$, Figure 2A). Further, the OS rate and median OS time in the low FAR group were also significantly higher than those in the high FAR group ( 89.2 vs $54.8 \%, 41.0$ vs 38.0 months, $\mathrm{P}<0.001$, Figure 2B). Kaplan-Meier analyses for OS based on the preoperative CEA and FAR in different $\mathrm{N}$ stages were also conducted (Supplement Figure 1). Only preoperative CEA could predict OS of patients with N0 and N2 stages (Supplement Figure 1A and E). However, pretreatment CEA could not predict OS of patients with N1 and N3 stage (Supplement Figure 1C and $\mathrm{G}$ ), as well as FAR in all $\mathrm{N}$ stages (Supplementary Figure 1B, D, F and $\underline{H})$.

\section{Prognostic Analysis Based on CEA-FAR}

As mentioned above, FAR and CEA are currently used as prognostic markers in GC patients, but whether CEA-FAR has the same prognostic value is still unclear. In this study, the OS was significantly different between the three CEAFAR groups (CEA-FAR $=0,1$, and $2: 88.9 \%, 65.0 \%$, and $46.9 \%$, respectively; $\mathrm{P}<0.001$, Figure $3 \mathrm{~A}$ ). In addition, even when patients were stratified based on clinical stage, CEA-FAR appeared to have a predictive value for pathological stage I-II and III when the (Figure 3B and C).

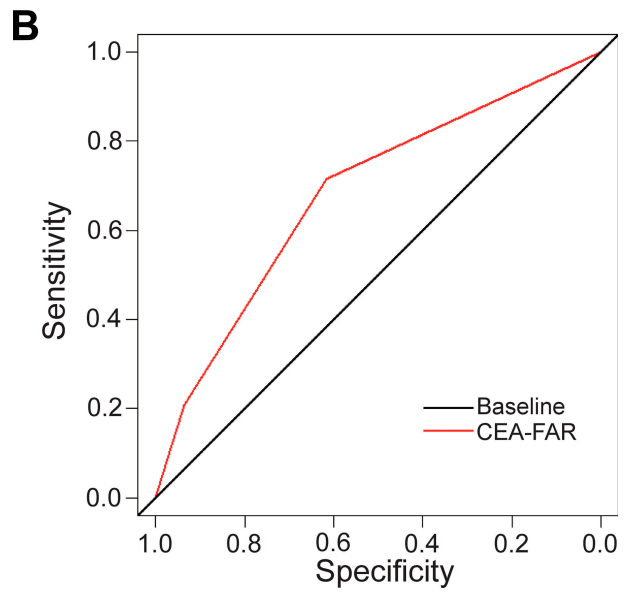

Figure I Receiver operating characteristics curve analysis of CEA, FAR (A) and CEA-FAR (B) for OS in GC patients. Note: CEA-FAR: CEA $<3.2$ and FAR $<0.086$ represent $0, C E A \geq 3.2$ or FAR $\geq 0.086$ represent I, CEA $\geq 3.2$ and FAR $\geq 0.086$ represent 2 . Abbreviations: GC, gastric cancer; CEA, carcinoembryonic antigen; FAR, fibrinogen/albumin ratio; OS, overall survival. 

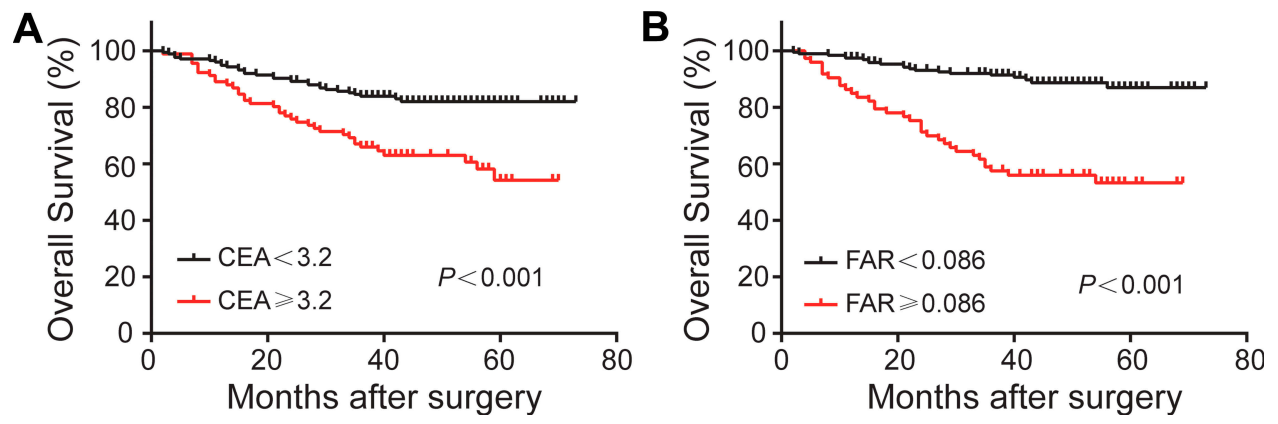

Figure 2 Kaplan-Meier survival curves for OS according to CEA (A) and FAR (B) in GC patients.

Abbreviations: OS, overall survival; GC, gastric cancer; CEA, carcinoembryonic antigen; FAR, fibrinogen/albumin ratio.
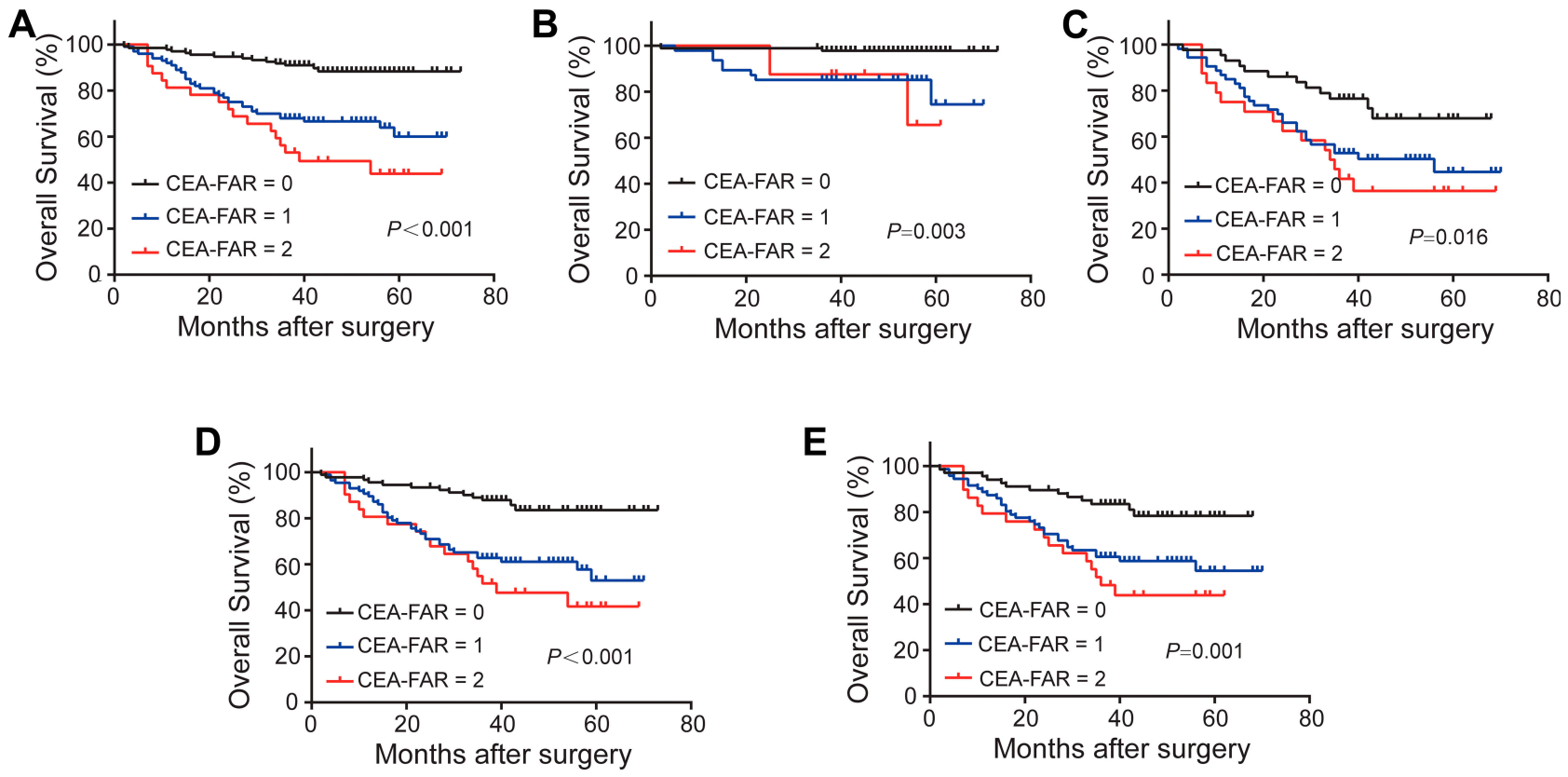

Figure 3 OS based on CEA-FAR in GC patients with stage I-III (A), I-II (B), III (C), advanced GC (D) and lymph node metastasis (E). Note: CEA-FAR: CEA $<3.2$ and FAR $<0.086$ represent $0, C E A \geq 3.2$ or FAR $\geq 0.086$ represent $I, C E A \geq 3.2$ and FAR $\geq 0.086$ represent 2 . Abbreviations: OS, overall survival; GC, gastric cancer; CEA, carcinoembryonic antigen; FAR, fibrinogen/albumin ratio.

Furthermore, CEA-FAR was a prognostic indictor for OS in advanced GC patients, who represents stage T1 regardless of lymph node involvement (Figure 3D) and patients with lymph node metastasis (Figure 3E). We also found significant differences in age $(\mathrm{P}<0.001)$, tumor size ( $\mathrm{P}<0.001)$, tumor invasion $(\mathrm{P}<0.001)$, lymph node metastasis $(\mathrm{P}<0.001)$, and TNM stage $(\mathrm{P}<0.001)$ (Table 3$)$ between the three groups upon analyzing the relationship between CEA-FAR and clinicopathological features.

\section{Univariate and Multivariate Survival Analyses}

To further identify the predictors of OS after gastrectomy, the clinicopathological variables were evaluated using univariate and multivariate analyses. The univariate analysis revealed that age (HR: 3.307, 95\% CI: 1.688-6.478, $\mathrm{P}=0.001$ ), tumor size (HR: 3.495 , 95\% CI: $1.871-6.528$, $\mathrm{P}<0.001$ ), FAR (HR: 2.621, 95\% CI: 1.618-4.244, $P<0.001$ ), CEA level (HR: 2.296, 95\% CI: 1.421-3.71, $\mathrm{P}=0.001$ ), CEA-FAR (CEA-FAR=1: HR: $2.87,95 \%$ CI: 1.636-5.034; CEA-FAR=2: HR: 4.918, 95\% CI: $2.463-$ 9.82, $\mathrm{P}<0.001$ ), and TNM stage (stage II: HR: $5.609,95 \%$ CI: 1.243-25.311, $\mathrm{P}=0.025$; stage III: HR: 20.615, 95\% CI: $5.023-84.615, \mathrm{P}<0.001)$ significantly correlated with patient prognosis (Table 4).

According to the multivariate analysis, CEA-FAR remained as a predictor for outcome (CEA-FAR $=1$ : HR: 1.642, 95\% CI: 0.922-2.923, $\mathrm{P}=0.092$; CEA-FAR $=2$ : HR: 
Table 3 The Clinicopathological Characteristic Stratified by the CEA-FAR Score

\begin{tabular}{|c|c|c|c|c|}
\hline Characteristics & $\begin{array}{l}\text { CEA-FAR } \\
0\end{array}$ & $\begin{array}{l}\text { CEA-FAR } \\
\mathrm{I}\end{array}$ & $\begin{array}{l}\text { CEA-FAR } \\
2\end{array}$ & $P$ value \\
\hline $\begin{array}{l}\text { Age (Years) } \\
\quad<60 \\
\geq 60\end{array}$ & $\begin{array}{l}61 \\
74\end{array}$ & $\begin{array}{l}22 \\
78\end{array}$ & $\begin{array}{l}6 \\
26\end{array}$ & $<0.001$ \\
\hline $\begin{array}{l}\text { Sex } \\
\qquad \text { Female } \\
\text { Male }\end{array}$ & $\begin{array}{l}62 \\
73\end{array}$ & $\begin{array}{l}19 \\
81\end{array}$ & $\begin{array}{l}10 \\
22\end{array}$ & $<0.001$ \\
\hline $\begin{array}{l}\text { Tumor size }(\mathrm{cm}) \\
\quad<3 \\
\geq 3\end{array}$ & $\begin{array}{l}75 \\
59\end{array}$ & $\begin{array}{l}29 \\
71\end{array}$ & $\begin{array}{l}4 \\
28\end{array}$ & $<0.001$ \\
\hline $\begin{array}{l}\text { Tumor location } \\
\text { Upper third } \\
\text { Middle third } \\
\text { Lower third }\end{array}$ & $\begin{array}{l}27 \\
35 \\
73\end{array}$ & $\begin{array}{l}29 \\
18 \\
53\end{array}$ & $\begin{array}{l}10 \\
6 \\
16\end{array}$ & 0.356 \\
\hline $\begin{array}{l}\text { Histological grade } \\
\text { Well differentiated } \\
\text { Poorly } \\
\text { differentiated }\end{array}$ & $\begin{array}{l}30 \\
105\end{array}$ & $\begin{array}{l}14 \\
86\end{array}$ & $\begin{array}{l}4 \\
28\end{array}$ & 0.185 \\
\hline $\begin{array}{l}\text { NLR } \\
\quad<2.17 \\
\geq 2.17\end{array}$ & $\begin{array}{l}85 \\
50\end{array}$ & $\begin{array}{l}37 \\
63\end{array}$ & $\begin{array}{l}13 \\
19\end{array}$ & $<0.001$ \\
\hline $\begin{array}{l}\text { Tumor depth } \\
\text { T1 } \\
\text { T2 } \\
\text { T3 } \\
\text { T4 }\end{array}$ & $\begin{array}{l}44 \\
19 \\
48 \\
24\end{array}$ & $\begin{array}{l}14 \\
12 \\
28 \\
46\end{array}$ & $\begin{array}{l}1 \\
3 \\
11 \\
17\end{array}$ & $<0.001$ \\
\hline $\begin{array}{l}\text { Lymph node } \\
\text { No } \\
\text { NI } \\
\text { N2 } \\
\text { N3 }\end{array}$ & $\begin{array}{l}68 \\
29 \\
18 \\
20\end{array}$ & $\begin{array}{l}29 \\
21 \\
14 \\
36\end{array}$ & $\begin{array}{l}3 \\
5 \\
8 \\
16\end{array}$ & $<0.001$ \\
\hline $\begin{array}{l}\text { TNM stage } \\
\text { I } \\
\text { II } \\
\text { III }\end{array}$ & $\begin{array}{l}53 \\
39 \\
44\end{array}$ & $\begin{array}{l}17 \\
32 \\
52\end{array}$ & $\begin{array}{l}1 \\
5 \\
24\end{array}$ & $<0.001$ \\
\hline
\end{tabular}

Note: CEA-FAR: CEA $<3.2$ and FAR $<0.086$ represent 0, CEA $\geq 3.2$ or FAR $\geq 0.086$ represent I, CEA $\geq 3.2$ and $F A R \geq 0.086$ represent 2 .

Abbreviations: CEA, carcinoembryonic antigen; FAR, fibrinogen/albumin ratio; NLR, neutrophil-to-lymphocyte ratio.

2.308, 95\% CI: $1.13-4.716, \mathrm{P}=0.022)$. These results show that age $(\mathrm{P}=0.012), \mathrm{CEA}-\mathrm{FAR}(\mathrm{P}=0.022)$, and TNM stage $(\mathrm{P}<0.001)$ are important prognostic variables associated with poor OS (Table 4).

\section{Discussion}

This study established the relationships between systemic inflammation, clinicopathological features, and survival in
GC patients with resectable tumors. We found that higher FAR was associated with a larger tumor size, poorer differentiation, more severe lymph node metastasis, and more advanced TNM stage. Similarly, high CEA also correlated with increased age, a larger tumor size, more lymph node metastasis, and more advanced TNM stage. Notably, this study reveals for the first time that CEA-FAR is a more effective prognostic marker than either CEA or FAR alone in GC patients undergoing radical gastrectomy. GC patients with $\mathrm{CEA}-\mathrm{FAR}=2$ group had worse prognoses than those with $\mathrm{CEA}-\mathrm{FAR}=0$, indicating that increased CEA-FAR is related to tumor burden and tumor progression, making it a promising prognostic marker in GC patients.

Elevated FAR was found to be an independent prognostic factor for poor survival in GC patients, which is consistent with findings in previous reports. For example, a study by Hwang et al showed that FAR can predict the survival of breast cancer patients. ${ }^{7} \mathrm{Xu}$ et al also found that elevated FAR is associated with poor prognosis and increased risk of recurrence of hepatocellular carcinoma. ${ }^{9}$ Collectively, these findings, along with the findings from the present study, show that high FAR has a prognostic importance for various malignant tumors.

Although the reasons underlying the association between increased FAR and poor prognosis is complex and has not been clarified, some mechanisms have been proposed. A hypercoagulable state is closely related to the development of malignant tumors. Fibrinogen decomposes to form fibrin, which provides a scaffold for growth, infiltration, and metastasis of tumor cells. ${ }^{12}$ Fibrinogen can also act as a ligand for various adhesion molecules, increasing the adhesion and binding between platelets and tumor cells and promoting their infiltration and metastasis. ${ }^{13}$ Fibrinogen is not only an important component of the coagulation system, but is also an acute phase response protein, making it an indicator of systemic inflammation. Previous studies have shown that fibrinogen plays an important role in inflammatory reactions and the synthesis of pro-inflammatory cytokines. ${ }^{14,15}$ Fibrinogen mediates the release of pro-inflammatory cytokines, which promotes the proliferation and progression of tumor cells. ${ }^{16}$ Clinically, Lee et al found that the plasma fibrinogen level was significantly higher in cancer patients than in patients with benign diseases, and fibrinogen levels increased during recurrence or metastasis. ${ }^{17}$ Pichler et al found that fibrinogen was associated with lymph node metastasis and clinical staging in cancer. ${ }^{18}$ In lung cancer, tumor cells can produce IL- 6 to stimulate secretion of fibrinogen. ${ }^{19}$ 
Table 4 Univariate and Multivariate Analyses of Prognostic Factors in GC Patients

\begin{tabular}{|c|c|c|c|c|}
\hline \multirow[t]{2}{*}{ Factors } & \multicolumn{2}{|l|}{ Univariate Analysis } & \multicolumn{2}{|l|}{ Multivariate Analysis } \\
\hline & HR (95\% Cl) & $P$ value & HR (95\% Cl) & $P$ value \\
\hline $\begin{array}{l}\text { Age(years) } \\
\quad<60 \\
\quad \geq 60\end{array}$ & I $3.307(1.688-6.478)$ & 0.001 & $2.406(1.213-4.77)$ & 0.012 \\
\hline $\begin{array}{l}\text { Sex } \\
\text { Female } \\
\text { Male }\end{array}$ & $1.776(1.013-3.115)$ & 0.045 & & \\
\hline $\begin{array}{l}\text { Tumor size }(\mathrm{cm}) \\
\quad<3 \\
\geq 3\end{array}$ & $3.495(1.87 I-6.528)$ & $<0.001$ & & \\
\hline $\begin{array}{l}\text { Tumor Location } \\
\text { Upper third } \\
\text { Middle third } \\
\text { Lower third }\end{array}$ & $\begin{array}{l}0.894(0.473-1.69) \\
I .496(0.856-2.617) \\
\mathrm{I}\end{array}$ & $\begin{array}{l}0.73 \\
0.158\end{array}$ & & \\
\hline $\begin{array}{l}\text { Histological grade } \\
\text { Well differentiated } \\
\text { Poorly differentiated }\end{array}$ & $\begin{array}{l}\mathrm{I} \\
0.77(0.393-1.508)\end{array}$ & 0.446 & & \\
\hline $\begin{array}{l}\text { FAR } \\
\qquad \begin{array}{l}<0.086 \\
\geq 0.086\end{array}\end{array}$ & I $2.621(1.618-4.244)$ & $<0.001$ & & \\
\hline $\begin{array}{l}\text { CEA }(\mathrm{ng} / \mathrm{mL}) \\
\quad<3.2 \\
\geq 3.2\end{array}$ & $\begin{array}{l}\mathrm{I} \\
2.296(|.42|-3.7 I)\end{array}$ & 0.001 & & \\
\hline $\begin{array}{l}\text { NLR } \\
\quad<2.17 \\
\geq 2.17\end{array}$ & $\begin{array}{l}\text { I } \\
3.063(1.799-5.213)\end{array}$ & $<0.001$ & & \\
\hline $\begin{array}{l}\text { CEA-FAR } \\
0 \\
1 \\
2\end{array}$ & $\begin{array}{l}\text { I } \\
2.87(1.636-5.034) \\
4.918(2.463-9.82)\end{array}$ & $\begin{array}{l}<0.001 \\
<0.001\end{array}$ & $\begin{array}{l}\text { I } \\
1.642(0.922-2.923) \\
2.308(1.13-4.716)\end{array}$ & $\begin{array}{l}0.092 \\
0.022\end{array}$ \\
\hline $\begin{array}{l}\text { TNM Stage } \\
\text { I } \\
\text { II } \\
\text { III }\end{array}$ & $\begin{array}{l}\text { I } \\
5.609(1.243-25.311) \\
20.615(5.023-84.615)\end{array}$ & $\begin{array}{l}0.025 \\
<0.001\end{array}$ & $\begin{array}{l}\text { I } \\
5.049(1.106-23.057) \\
18.759(4.354-80.812)\end{array}$ & $\begin{array}{l}0.037 \\
<0.001\end{array}$ \\
\hline
\end{tabular}

Note: CEA-FAR: CEA $<3.2$ and FAR $<0.086$ represent $0, C E A \geq 3.2$ or FAR $\geq 0.086$ represent $I, C E A \geq 3.2$ and FAR $\geq 0.086$ represent 2 .

Abbreviations: GC, gastric cancer; CEA, carcinoembryonic antigen; FAR, fibrinogen/albumin ratio; TNM, tumor-node-metastasis; HR, hazard ratio; $\mathrm{Cl}$, confidence interval; NLR, neutrophil-to-lymphocyte ratio.

Perisanidis et al proposed that reducing fibrinogen concentration could prolong survival of patients with solid tumors. ${ }^{20}$

Albumin, which is the most abundant protein in plasma, is commonly used to assess nutritional status in clinical practice. Hypoalbuminemia indicates a poor nutritional status. Malnutrition can lead to the decline of immune function in cancer patients, thus increasing the risk of postoperative complications and tumor progression. ${ }^{21}$ Previous studies have reported that hypoalbuminemia is associated with disease progression and poor prognosis in patients with colon cancer, ${ }^{22}$ pancreatic cancer, ${ }^{23}$ non-small cell lung cancer, ${ }^{24}$ ovarian cancer, ${ }^{25}$ and GC. ${ }^{26}$

Furthermore, this study shows that preoperative CEA is an independent prognostic factor of survival, consistent 
with previous studies. Zhan et al reported that preoperative CEA elevation is a predictor of OS in early GC. ${ }^{10}$ Guo et al believe that CEA alone or in combination with CA199 and CA72-4 can be used as a predictor of cancer-specific survival and is important in predicting survival and informing treatment decisions in $\mathrm{GC} .^{27}$

Based on these findings, we used the combination of CEA level and FAR (CEA-FAR) as a novel biomarker in $\mathrm{GC}$ and found that it is a promising predictor of prognosis. Tumor progression is closely related to both patient and tumor characteristics. Elevated CEA level is associated with tumor invasion and metastasis, while FAR reflects the patient's inflammatory status, coagulation function, and nutritional status. Here, we confirmed that the combination of CEA and FAR can effectively predict the survival of GC patients, and that its predictive capability is superior to that of either CEA or FAR alone.

However, this study also has some limitations. First, this was a single-center retrospective study and was likely affected by selection bias. Second, we cannot eliminate the potential bias due to the difference in the types of surgery and postoperative chemotherapy regimens. Therefore, the clinical value of preoperative CEA-FAR as a prognostic predictor in GC should be further clarified in larger, multi-center prospective studies.

\section{Conclusion}

Preoperative CEA-FAR is an independent prognostic factor of OS in GC patients. Its convenience, low cost, and high repeatability makes it a valuable indicator of prognosis in GC patients. The findings of this study provide a basis for more accurate and individualized treatment.

\section{Acknowledgments}

This study was supported by the Medical Health Science and Technology Project of Zhejiang Provincial Health Commission (Grant No. 2017209495).

\section{Disclosure}

The authors report no conflicts of interest in this work.

\section{References}

1. Chen W, Zheng R, Baade PD, et al. Cancer statistics in China, 2015. CA Cancer J Clin. 2016;66(2):115-132. doi:10.3322/caac.21338

2. Liang Y, Wang W, Que Y, et al. Prognostic value of the fibrinogen/ albumin ratio (FAR) in patients with operable soft tissue sarcoma. BMC Cancer. 2018;18(1):942. doi:10.1186/s12885-018-4856-x

3. Wen L, Guo L, Zhang W, et al. Cooperation between the inflammation and coagulation systems promotes the survival of circulating tumor cells in renal cell carcinoma patients. Front Oncol. 2019;9:504. doi: $10.3389 /$ fonc. 2019.00504
4. Wu ZJ, Xu H, Wang R, et al. Cumulative score based on preoperative fibrinogen and pre-albumin could predict long-term survival for patients with resectable gastric cancer. $J$ Cancer. 2019;10 (25):6244-6251. doi:10.7150/jca.35157

5. Liu X, Liu Z, Lin E, Chen Y, Sun X, Zhou Z. A cumulative score based on preoperative fibrinogen and the neutrophil-lymphocyte ratio to predict outcomes in resectable gastric cancer. Cancer Manag Res. 2018;10:3007-3014. doi:10.2147/CMAR.S174656

6. Gupta D, Lis CG. Pretreatment serum albumin as a predictor of cancer survival: a systematic review of the epidemiological literature. Nutr J. 2010;9:69. doi:10.1186/1475-2891-9-69

7. Hwang KT, Chung JK, Roh EY, et al. Prognostic influence of preoperative fibrinogen to albumin ratio for breast cancer. $J$ Breast Cancer. 2017;20(3):254-263. doi:10.4048/jbc.2017.20.3.254

8. Xu WY, Zhang HH, Xiong JP, et al. Prognostic significance of the fibrinogen-to-albumin ratio in gallbladder cancer patients. World J Gastroenterol. 2018;24(29):3281-3292. doi:10.3748/wjg.v24.i29.3281

9. Xu Q, Yan Y, Gu S, et al. A novel inflammation-based prognostic score: the fibrinogen/albumin ratio predicts prognoses of patients after curative resection for hepatocellular carcinoma. J Immunol Res. 2018;2018:4925498. doi:10.1155/2018/4925498

10. Feng F, Tian Y, Xu G, et al. Diagnostic and prognostic value of CEA, CA19-9, AFP and CA125 for early gastric cancer. BMC Cancer. 2017;17(1):737. doi:10.1186/s12885-017-3738-y

11. Tan Z, Zhang M, Han Q, et al. A novel blood tool of cancer prognosis in esophageal squamous cell carcinoma: the fibrinogen/albumin ratio. J Cancer. 2017;8(6):1025-1029. doi:10.7150/jca.16491

12. Repetto O, De Re V. Coagulation and fibrinolysis in gastric cancer. Ann N Y Acad Sci. 2017;1404(1):27-48. doi:10.1111/nyas.13454

13. Palumbo JS, Talmage KE, Massari JV, et al. Platelets and fibrin(ogen) increase metastatic potential by impeding natural killer cell-mediated elimination of tumor cells. Blood. 2005;105(1):178-185. doi:10.1182/blood-2004-06-2272

14. Luyendyk JP, Schoenecker JG, Flick MJ. The multifaceted role of fibrinogen in tissue injury and inflammation. Blood. 2019;133 (6):511-520. doi:10.1182/blood-2018-07-818211

15. Jenkins DR, Craner MJ, Esiri MM, DeLuca GC. Contribution of fibrinogen to inflammation and neuronal density in human traumatic brain injury. J Neurotrauma. 2018;35(19):2259-2271. doi:10.1089/neu.2017.5291

16. Zhang F, Wang Y, Sun P, et al. Fibrinogen promotes malignant biological tumor behavior involving epithelial-mesenchymal transition via the $\mathrm{p}-\mathrm{AKT} / \mathrm{p}-\mathrm{mTOR}$ pathway in esophageal squamous cell carcinoma. J Cancer Res Clin Oncol. 2017;143(12):2413-2424. doi:10.1007/s00432-017-2493-4

17. Lee SE, Lee JH, Ryu KW, et al. Preoperative plasma fibrinogen level is a useful predictor of adjacent organ involvement in patients with advanced gastric cancer. $J$ Gastric Cancer. 2012;12(2):81-87. doi:10.5230/jgc.2012.12.2.81

18. Pichler M, Hutterer GC, Stojakovic T, Mannweiler S, Pummer K, Zigeuner R. High plasma fibrinogen level represents an independent negative prognostic factor regarding cancer-specific, metastasis-free, as well as overall survival in a European cohort of non-metastatic renal cell carcinoma patients. Br J Cancer. 2013;109(5):1123-1129. doi:10.1038/bjc.2013.443

19. Yamaguchi T, Yamamoto Y, Yokota S, Nakagawa M, Ito M, Ogura T. Involvement of interleukin- 6 in the elevation of plasma fibrinogen levels in lung cancer patients. Jpn J Clin Oncol. 1998;28 (12):740-744. doi: $10.1093 / \mathrm{jjco} / 28.12 .740$

20. Pergialiotis V, Doumouchtsis SK, Perrea D, Vlachos GD. The impact of underweight status on the prognosis of ovarian cancer patients: a meta-analysis. Nutr Cancer. 2016;68(6):918-925. doi:10.1080/ 01635581.2016 .1190021

21. Yamamoto M, Saito H, Uejima C, et al. Combination of serum albumin and cholinesterase levels as prognostic indicator in patients ith colorectal cancer. Anticancer Res. 2019;39(2):1085-1090. doi:10.21873/anticanres. 13217 
22. Li Z, Xu Z, Huang Y, et al. Prognostic values of preoperative platelet-to-lymphocyte ratio, albumin and hemoglobin in patients with non-metastatic colon cancer. Cancer Manag Res. 2019;11:3265-3274. doi:10.2147/CMAR.S191432

23. Hang J, Xue P, Yang H, et al. Pretreatment C-reactive protein to albumin ratio for predicting overall survival in advanced pancreatic cancer patients. Sci Rep. 2017;7(1):2993. doi:10.1038/s41598-017-03153-6

24. Zhang L, Zhang H, Yue D, et al. The prognostic value of the preoperative albumin to alkaline phosphatase ratio in patients with non-small cell lung cancer after surgery. Thorac Cancer. 2019;10 (7):1581-1589. doi:10.1111/1759-7714.13107
25. Liu Y, Chen S, Zheng C, et al. The prognostic value of the preoperative c-reactive protein/albumin ratio in ovarian cancer. BMC Cancer. 2017;17(1):285. doi:10.1186/s12885-017-3220-x

26. Mao M, Wei X, Sheng $H$, et al. C-reactive protein/albumin and neutrophil/lymphocyte ratios and their combination predict overall survival in patients with gastric cancer. Oncol Lett. 2017;14 (6):7417-7424. doi:10.3892/ol.2017.7179

27. Guo J, Chen S, Li S, et al. A novel classifier based on three preoperative tumor markers predicting the cancer-specific survival of gastric cancer (CEA, CA19-9 and CA72-4). Oncotarget. 2018;9 (4):4814-4822. doi:10.18632/oncotarget.23307

\section{Publish your work in this journal}

Cancer Management and Research is an international, peer-reviewed open access journal focusing on cancer research and the optimal use of preventative and integrated treatment interventions to achieve improved outcomes, enhanced survival and quality of life for the cancer patient
The manuscript management system is completely online and includes a very quick and fair peer-review system, which is all easy to use. Visit http://www.dovepress.com/testimonials.php to read real quotes from published authors. 